\title{
SAĞLIK ALANINDA GÜMÜŞ YAKALILAR
}

\section{SILVER COLLAR IN HEALTH}

\author{
Nilgün Bozbuğa $^{1}$ (D), Eda Yılmaz Alarçin² (D)
}

${ }^{1}$ İstanbul Üniversitesi İstanbul Tıp Fakültesi, Kalp ve Damar Cerrahisi Anabilim Dalı, İstanbul, Türkiye

${ }^{2}$ İstanbul Üniversitesi-Cerrahpaşa, Sağlık Bilimleri Fakültesi, Sağlık Yönetimi Bölümü, Hastane İşletmeciliği Anabilim Dalı, İstanbul, Türkiye

ORCID ID: N.B. 0000-0002-4401-5250; E.Y.A. 0000-0002-6100-1272

Atıf/Citation: Bozbuga N, Yilmaz Alarcin E. Silver collar in health. Sağlık Bilimlerinde İleri Araşttrmalar Dergisi 2022;5(1):71-77. https://doi.org/10.26650/JARHS2022-1037623

öz

Toplumlarda demografik, sosyokültürel ve ekonomik yapının değişimi, teknolojinin hızlı gelişimi ve çalışma kültürünün farklılaşması nedenleriyle işgücünün yapısı da değişime uğramakta ve yeni kavramlar ortaya çıkmaktadır. Bu kavramsal çalışmada daha önce insan kaynakları terminolojisi ve literatüründe yer almamış olan "gümüş yakalılar" kavramının özellikle sağlık sektöründe hizmet üreten, hekimler hariç, sağlık çalışanlarının tanımlanmasında kullanılması önerilmektedir. Kariyer alanları olarak mesleki ve kurumsal bağlılık, örgüt kültürünü yaşatma ve örgüt iklimini sürdürme, sorun çözme, uzun süreli sosyal iletişim özellikleriyle hemşireler ve yardımcı sağlık çalışanları için gümüş yakalılar tanımlamasının uygunluğu bağlamında, niteliksel yöntem araştırmalarına öncü bir deneme sunulmaktadır.

Anahtar Kelimeler: Gümüş yakalılar, sağlık çalışanları, insan kaynakları

\section{ABSTRACT}

Due to the change in demographic, socio-cultural and economic structure in societies, the rapid development of technology and the differentiation of working culture, the structure of the workforce is also changing, and new concepts are emerging. In this conceptual study, it is suggested that the concept of "silver collars", a phrase which has not been included in human resources terminology and literature before, could be used in the definition of health workers (excluding physicians), who provide services in the healthcare sector. Our pioneering essay discusses which nurses and allied health workers will be covered within the definition of silver collars with their professional and institutional commitment as career fields, keeping the organizational culture alive, maintaining the organizational climate, problem solving, and long-term social communication.

Keywords: Silver collar, healthcare workers, human resources

\section{Giriş}

Toplumlarda demografik, sosyokültürel ve ekonomik yapının değişimi, teknolojinin hızlı gelişimi ve çalışma kültürünün farkIılaşması nedenleriyle işgücünün yapısı da değişime uğramaktadır. Sürekli gelişen teknolojinin etkisi altında kurumsal varlıklarını sürdürme çabasında olan kuruluşlar, üretim kaynaklarını ve çalışma koşullarını her zamankinden daha etkin kullanmak zorunda kalmaktadırlar (1). Tarihsel süreçte işgücünün çalışma kültürünün değişmesine koşut olarak, kurumların sahip oldukları en değerli kaynaklardan birinin "beşeri kaynaklar" olduğu, bu bağlamda kurumların varlık değeri içinde "entelektüel sermaye" oranının artmakta olduğu görüşü ağırlık kazanmıştır.

Bilgi ekonomisi ve endüstri 4.0 dönüşümünün ekonomik ve sosyal alanlar üzerindeki etkisi özellikle insan kaynakları yönetimi açısından üzerinde durulması gereken konulardan birini oluşturmaktadır. Bu görüşü destekler biçimde bilgi odaklı, bilgi üretmeye dayalı çalışma ilkelerini benimsemiş yeni meslek türleriyle bağlantılı yeni çalışan sınıflarının ortaya çıktıkları görülmektedir (2). Sonuç itibarıyla çalışma biçimlerinin değişmesi, bireysel ve toplumsal alanda birtakım köklü değişimlere de sebep olmaktadır. İş hayatı ve özel hayat, çalışma süresi ve özgür zaman arasındaki ayrımlar giderek zorunluluklar nedeniyle bulanıklaşmakta, sınırlar/kategorik ayrımlar belirsizleşmektedir. Meslek/kariyerin yaşamın her alanında belirleyici olması, çalışanın hayatının meslek algısı etrafinda şekillenmesi, bu doğrultuda mesleğin bireye kimlik ve aidiyet kazandırması zorunlu bir rotaya dönüşmekte; klasik anlamdaki meslek anlayışı ve mesleğin çalışana kimlik ve aidiyet kazandırma yönü geçen yüzyıla ait mavi/beyaz yakalı tanımlarının çok ötesinde şekillenmektedir.

Sorumlu Yazar/Corresponding Author: Nilgün BOZBUĞA E-mail: nilgun.bozbuga@istanbul.edu.tr

Başvuru/Submitted: 17.12.2021 • Kabul/Accepted: 23.12.2021 • Online Yayın/Published Online: 02.02.2022 
Yaka kavramı, işletmelerin en değerli varlıklarından biri olarak kabul edilen çalışanların niteliklerine ve pozisyonlarına yönelik birtakım sınıflandırmaları ve tanımlamaları içermektedir. El emeğine dayalı veya vasfinda olma; ücret düzeyi, eğitim, sermaye vs. kaynaklara erişim şekli gibi farklılıklar çerçevesinde ortaya çıkmaktadır (3). Yaka temelli tanımlamalar işletmelere çalışanların yönetimi açısından kolaylık sağlamaktadır. Mavi ve beyaz yaka kavramının uzun yıllardır süregelen yaygın kullanımının yanı sıra çalışanların hangi iş kolunda çalıştıklarını ya da hangi niteliklere sahip olduklarını tanımlamak veya gruplamak amacıyla yaka rengi referanslı sınıflandırma geleneği, kapsamı genişleyerek sürdürülmektedir.

Ağırlıklı olarak kol gücü ile çalışan $(4,5)$ "mavi yakalılar", denetim dışı, yönetsel olmayan ve genellikle saatlik ücretli işlerde çalışan; çoğunlukla orta öğretimi geçmeyen düşük eğitim düzeyine sahip; düşük beceriler gerektiren işleri yapan grubu ifade etmektedir (6). Üretim bandında giydikleri üniforma benzeri mavi renkli iş kıyafetlerinden dolayı bu benzetme yoluyla adlandırılmışlardır. Mavi yakalılar üretim, madencilik, inşaat, mekanik, servis, teknik kurulum ve diğer fiziksel çalışma yöntemlerini kullanan bir sınıfi oluşturmaktadır $(3,7)$.

Bir diğer grup olan "beyaz yakalılar" görevleri gereği kelimeler, sayılar, fikirler, şekiller, bilgi gibi verilere dayanan ve ağırlıklı olarak beyin gücü ile çalışan grubu temsil etmektedir $(4,6)$. Beyaz yakalılar profesyonel, yönetimsel veya idari işler yapan, ofiste çalışan kişileri ifade etmektedir. Ofis çalışanlarının giydikleri beyaz gömleklerinden adını alan grup, mavi yakalılara göre fiziksel olarak daha az zahmet gerektiren ve daha yüksek ücretli işleri yürütmektedirler $(3,5)$.

İnsan emeğinin yeni dönemdeki versiyonunun iletişim ve bilişim teknolojisine kaymasıyla yeni bir tanımlama olarak "altın yakalılar" kavramı ortaya çıkmıştır. Bilgi toplumlarının en kalıcı özelliği olarak üretim için işçi ve makinelerin koordinasyonu yerine bilgi etrafinda örgütlenmelerin üzerinde durulmaktadır (8). Bu çerçevede yönetim bilimci Peter F. Drucker elli yıl öncesinden, yirmi birinci yüzyılın en değerli varlığının "bilgi işçileri" olacağı fikrini ortaya atmıştır (9). Farklı düşünen, farklı davranan, farklı ihtiyaçları olan ve bilgi işçileri olarak da ifade edilen altın yakalılar büyük ölçüde beyin gücüyle ön plana çıkan çalışanları içermektedir (10). Altın yakalılar kavramı yüksek düzeyde performans gösteren ve yüksek ücretin yanı sıra özel avantajlar talep eden yetenekli ve üniversite eğitimli çalışanları ifade etmektedir. Altın yakalılar zeki, bağımsız ve yenilikçi olma eğilimindedirler ve bu çalışanlar işletme ve toplum için "değerli" olan bir grubu temsil etmektedirler. Bilgi teknolojileri profesyonelleri, yazılımcılar, analistler, akademisyenler, hekimler, hukukçular, kamu ve özel sektör yöneticileri, mühendisler vs. bu grupta yer alan çalışanları örneklemektedir. Rutin olmayan görevleri yerine getirme ve problem çözme yetenekleri, yaratıcılık ve zekâları altın yakalıların neden değerli olduklarını açıklayan özellikler arasında sıralanmaktadır $(8,9,11-13)$.

Dünya savaşları etkisi ile ortaya çıkan "pembe yakalılar", kadın kimliğiyle tanımlanan, beyaz yakalılara göre daha düşük ücret ve prestij sağlayan, sınırlı kariyer imkanına sahip olan; mavi yakalılara göre daha az beden gücü gerektiren, daha temiz ve rahat çalışma ortamında yürütülen büro ve idari destek pozisyonlarını ifade etmektedir. Kadınların ailedeki rolleri yaklaşımına uygun olarak bakım ve güzellik endüstrisi odaklı çalışanlar ile hemşirelik, sekreterlik, satş temsilciliği, anaokulu öğretmenliği gibi meslekler bu grupta değerlendirilmektedir (14-19). Yaşanan teknolojik gelişmeler, ekonomik koşullar ve enerji politikaları ile "yeşil yakalı" olarak adlandırılan bir başka grup daha ortaya çıkmıştır (20). Özellikle çevre bilincinin, endüstriyel işletmeler gibi örgütler için bir endişe haline gelmesiyle yeşil yakalı kavramının geliştiği belirtilmektedir (21). Bu kavram, sürdürülebilirlik veya çevre bilinci gerektiren işlerde çalışan insanları tanımlamak için giderek daha fazla kullanılmaktadır $(22,23)$. Yeşil yakalılar sürdürülebilirliği artırmayı, bilinçli enerji kullanımını, atkları ve kirliliği azaltmayı amaçlayan görevleri yerine getirmektedirler. Bu işgücü, yeni yaratılan işleri içermekle birlikte hem çevre hem de çalışan üzerindeki etkileri iyileştirmek için mevcut işlerin "yeşilleştirilmesini" de kapsamaktadır (24). Bu çerçevede enerji verimli binaların ve araçların yapımından yenilenebilir enerji üretimine (örneğin biyoyakıt geliştirme) kadar birçok endüstri alanını içermektedir (25). Yeşil yakalılar evsel atkları geri dönüştürme, işe bisikletle gitme, yaşam alanlarında ve iş yerlerinde enerji tasarrufu sağlayan değişiklikler yapma, enerji tasarrufu teknolojisinin kullanımını teşvik etme, geleceğin enerji verimli teknolojileriyle ilgilenme, geri dönüşüm, çevreye zararlı ürünlerden kaçınma gibi konularda hassasiyet göstermektedirler (21).

Mavi/beyaz yaka dışında kullanılan bir başka yaka kavramı da "gri yakalılar"dır. Batılı ülkelerde ve işletmelerde işgücü içerisinde "grileşen", bir başka ifadeyle yaşlanan nüfusu tanımlamak için kullanılan gri yakalı, diğer bir görüşe göre de mavi ve beyaz yakalı çalışanlar arasında kalan yüksek teknoloji teknisyenlerini, yüksek vasıflı iş̧̧ileri, eğitimli teknisyenleri, bilgi iş̧̧ilerini, yarı zamanlı çalışanlar gibi bir grubu ifade etmektedir $(5,26)$. "Siyah yakalılar" ise endüstrideki "el" işçilerini (27), madencilik veya petrol endüstrisindeki çalışanları, bazen de karaborsa faaliyetlerinde bulunan kişileri tanımlamaktadır (28). Bütün bu yaka kavramlarının yanı sıra kısıtlı alanda bazı grupları tanımlamada örneğin mahkûmlar tarafindan giyilen turuncu tulumları çağrıştırması nedeniyle cezaevi çalışanları için "turuncu yakalılar", devlet işçileri için "kırmızı yakalılar" kavramı kullanılmaktadır. "Yeni yakalılar", renk tanımından bağımsız bir kavram olarak eğitim düzeyi yüksek ve modern teknoloji alanında çalışanları tanımlanmaktadır $(28,29)$. "Açık yakalılar" kavramı renk tanımlaması içermemekle birlikte, "tele" çalışma koşulları sonucu ortaya çıkan, uzaktan kurum dışı/evden çalışan grubu ifade etmektedir $(30,31)$. Benzer yaklaşımla "yeni yakalılar", "dijital yakalılar", "mobil yakalılar" iletişim ve bilişim teknolojilerini yoğun olarak kullanarak çalışanları ifade etmek amacıyla kullanılmaktadır (28). "Sanal yakalılar" terimi ise fiziksel ve sanal olarak görev gerçekleştiren robotları tanımlamakta kullanılmaya başlanmıştı. Sanal yaka kavramı siber suçlarla da ilişkilendirilerek, sanal ortamda yüksek bilişim becerisi temelli çevirimiçi suçlular ve firsatçılar için de kullanılmaktadır (32).

Bu çalışmada daha önce insan kaynakları terminolojisi ve alanyazınında (literatür) yer almamış olan "gümüş yakalılar" 
kavramının özellikle sağlık sektöründe hizmet üreticileri olan, hekimler hariç, sağlık çalışanlarının tanımlanmasında kullanılması önerilmektedir (33). Bu kavramsal çalışmanın amacı, başta sağlık olmak üzere hizmet sektöründe gümüş yakalılar olarak tanımlanması önerilen çalışanların mesleki kariyer kavramlarının, algı ve anlayışlarının, değişim ve dönüşümlerinin daha iyi anlaşılabilmesi ve analiz edilebilmesinde yürütülecek niteliksel yöntem araştırmalarına öncül (antecedent) bir deneme olmasıdır.

\section{GÜMÜŞ}

Gümüş, Latince karşılığı "argentum" ve simgesi "Ag" olan, beyaz, parlak, değerli bir metalik elementtir. Gümüş periyodik tabloda ağır metaller grubu içinde yer almaktadır. Gümüşün atom numarası 47; atom ağırlığı 107,87; özgül ağırlığı 10,5 g/cm³ ve çoğu bileşiklerinde +1 değerliklidir. Doğal gümüş saf halde veya altın, bakır ve civa metalleriyle alaşım halinde argentit $\left(\mathrm{Ag}_{2} \mathrm{~S}\right)$ ve gümüş klorür $(\mathrm{AgCl})$ halinde bulunan, nanoteknoloji için uygun yapıda bir elementtir (34).

Eski çağlardan beri bilinen, değerli bir maden olan, değişim aracı olarak veya para ve takı yapımında kullanılan gümüş, altın ve bakırdan sonra keşfedilmiştir. Gümüş, M.Ö. 3100 yıllarında Antik Mısır'da ve M.Ö. 2500 yıllarında Çin ve Pers İmparatorluklarında kullanılmıştır. Antik Yunan uygarlığında Atina'da kullanılmaya başlanmış olmakla birlikte gümüşü ilk olarak Romalıların işlemeye başladıkları bilinmektedir (35).

Gümüş, ışığı çok iyi yansıtan, elektrik ve ısıyı çok iyi ileten, kolayca işlenerek şekil verilebilen bir metaldir. Gümüş kolay paslanmamakta; atmosferde oksitlenmeye karşı dirençli olduğundan bakırdan daha zor, altından ise daha kolay oksitlenmektedir. Gümüş üzerindeki kararmanın nedeni, havadaki hidrojen sülfürle oluşan birleşimdir. Gümüş atmosferde parlaklığını kaybederek donuklaşmaktadır. Gümüş, asitlere ve bazı organik bileşiklere dayanıklı olmakla birlikte, nitrik asit ve derişik sıcak sülfürik asitte kolayca eritilebilmektedir. Yumuşak olduğundan mekanik kuvvete karşı direnci az olması nedeniyle gümüş, daha sert diğer metallerle alaşımlar halinde kullanılmaktadır. Başta elektronik, bilgisayar, fotoğrafçılık ve boya endüstrisinde olmak üzere, diş hekimliğinde ve ilaç üretiminde, para basımında, süs eşyası ve takı yapımında, ayna sırlarının üretiminde kullanıldığı gibi pillerden yapay yağmur yağdırmaya varıncaya kadar kimya endüstrisinde yaygın kullanım alanına sahiptir. Toz halinde gümüş, cam ve ahşabı elektrik iletkeni yapmak için yeni seramik tipi kaplama işlerinde de kullanılmaktadır. Gümüş iyonlarından, acil durumlarda deniz suyundan içilebilir su elde etmek için de yararlanılabilmektedir. Tıpta antiseptik olarak yara ve yanık tedavisinde kullanımı mevcuttur (36).

Hemşire ve diğer yardımcı sağlık çalışanları için gümüş yakalı kavramının seçiminde gümüşün yarar ve niteliklerinden, sağalt-cı özelliğinin olmasından yola çıkılmıştı. Ayrıca gümüşün ısıyı ve ışığı yansıtma özellikleri ile yarattğı algı da sağlık profesyonelleri ile ilişkilendirilmiştir. Gümüşün değerli bir element olarak nitelendirilmesinin, hemşire ve yardımcı sağlık çalışanlarına yönelik "değerli" mesajını pekiştirmesi hedeflenmektedir.

\section{GÜMÜŞ YAKALILARIN KIMLIK ÖZELLIKLERi}

Gümüş yakalı tanımı kapsamına alınan çalışanların temel niteliklerinin anlaşılmasında; sağlık hizmeti üretiminde iş-meslek anlayışları, zaman-mekân algıları ve kullanım biçimleri, günlük yaşamlarıyla iş yaşamları arasındaki ilişkiler, kimlik ve aidiyet kazanma özellikleri gözden geçirilerek, çalışanlarda meslek kavramının içselleştirilmesi ve sağlık alanında çalışmanın günlük yaşamdaki değişmelere yansıması, potansiyel fizyolojik ve psikolojik risklere maruzlukları gibi iş yaşamıyla bağlantılı özelliklerin "gümüş yakalılar" kavramı ile ilişkilendirilerek irdelenmesi amaçlanmıştır (37).

Gümüş yakalı çalışanlar grubunun yapılan işi ve mesleği tanımlama, işin değeri ve anlamı, çalışma zamanını kullanma biçimleri ve zaman algıları, mekânı kullanma biçimleri ve mekân algıları, kariyer algıları, kariyer beklentileri, iş tatmini ve motivasyonları, sınıf ve statü algıları, bağlılık ve aidiyet, yabancılaşma, kimlik tanımlaması ve kişilik gelişimi konularındaki bakış açıları yorumlanmaya çalışılmıştır. İnsan kaynakları yönetimi açısından sağlık çalışanlarının sayısal, zamana dayalı ve işlevsel nitelikleri, çalışma biçimlerinin kurum performans ve ücret yönetimine etkileri, çalışma düzenlerinin gözetim ve/veya denetimleri ile ilgili araştırma konuları önem taşımaktadır (38). Diğer taraftan hemşirelik mesleği, kadınlara özgü bakım veren bir iş olmaktan çıkarak eğitim ve uygulama tekniklerindeki gelişmelerle meslek ölçütleri belirlenmiş, ayrı bir disiplin halinde sağlık ekibinin vazgeçilmez bir ögesi konumunu kazanmıştır (39).

Gümüş yakalıların avantaj oluşturan özellikleri aşağıdaki biçimde sıralanabilir:

- "Ben" yerine, "biz" öznesini daha çok kullanmaları,

- Ekip çalışması ve başarısını bireysel çalışma ve başarıya tercih etmeleri,

- Yaptıkları işleri sahiplenmeleri,

- Işlerini severek yapmaları ve tecrübelerini kullanmaları,

- Sadece iş hayatında değil, aile hayatlarında da sorumluluk sahibi olmaları,

- Süreç odaklı olmaları; koşulları oluşturmaya ve takım çalışmasına yatkınlık göstermeleri,

- Hiyerarşiye uyum göstermeleri ve statü beklentisi taşımaları,

- Kolay motive olabilmeleri ve kendi kendilerini motive edebilmeleri; motivasyonlarının kolay bozulmaması,

- Alanı geniş olmasa da yakın çevrelerine liderlik edebilmeleri ve çevrelerinin motivasyonuna katkı sağlayabilmeleri,

- Eğitime ve öğrenmeye açık, desteklendiklerinde eğitime istekli olmaları,

- Öğrenirken öğretme, danışmanlık ve koçluk, olumlu pekiştirme yapabilmeleri, 
- Teknolojiyi (kısıtlı olsa da) kullanabilmeleri, eğitimle teknolojiye uyum sağlayabilmeleri,

- E-eğitime yatkın olmaları ve sosyal medyadan yararlanabilmeleri,

- Küçük çaplı değişimlere uyum göstermeleri,

- Gelecek beklentilerinin yüksek olması; sevmedikleri işleri de yapabilme özelliklerinin bulunması,

- Küçük çaplı sorunlara öneriler ve pratik çözümler üretebilmeleri,

- Günlük veya kısa vadeli proje geliştirebilmeleri,

- Dikkatli ve detaycı olmaları,

- Mücadeleye ve zor koşullara dayanıklı ve disiplinli olmaları,

- Yardımcı ve kolaylaştırıcı olmaları,

- Şefkatli (genellikle) olmaları,

- Uyum becerisi, sabırlı davranma ve şükür özellikleri taşımaları,

- Güvenilir, kolay reddetmeyen, gerçekçi özellikler taşımaları,

- Yoksunluğu tanıma, gerektiğinde kabullenme özelliklerinin bulunması,

- Kurum içi aktivitelerde katılımcı ve yarışmacı olmaları,

- Kolay memnuniyet göstermeleri,

- Kibir ve kendini aşırı beğenme özelliklerinin az olması,

- Eleştiriye pek açık olmasalar da iletişime açık olmaları,

- İyi bir iletişim ağı kurma yeteneklerinin bulunması,

- Örgütsel hafizayı taşıma ve sürdürme özellikleri taşımaları,

- Örgüt kültürüne sahip çıkmaları; paylaşılan geleneklere bağııık göstermeleri; alışkanlıkları sürdürme, inançları, değerleri ve normları yaşatma yeteneklerinin bulunması,

- Çalıştıkları kuruma değer katmalarıdır.

Gümüş yakalıların dezavantaj oluşturan özellikleri ise şu şekilde sıralanabilir:

- Bilgiyi zaman ve mekândan bağımsız elde etmede isteksiz olabilmeleri, standart bilgiyi tercih etmeleri,

- Genellikle sosyal bilimler, temel bilimler ve teknik eğitimlerinin sınırlı olması,
- Teknolojiyi (genellikle) az ya da sınırlı kullanmaları,

- Olaylara "ne" ve "neden" soruları yerine "kim" sorusu sorarak yaklaşmaları,

- Genellikle alışkanlıklarına bağı, tutucu olmaları,

- Büyük değişimlere yavaş adaptasyon ya da tepki göstermeleri,

- Çıkarımlarını haklı gösterme çabasında olmaları,

- Yetkilerini fazlaca koruma eğiliminde olmaları,

- Yetki paylaşımı yapmama eğilimi göstermeleri,

- Işslevsel yetki ve sorumluluk sınırlarının belirsiz olmasını desteklemeleri,

- Sorun olduğunda çevredekileri suçlama eğilimde olmaları,

- Çözüm için hızlı harekete geçme refleksi gösterememeleri,

- Ürettikleri projeleri gerçekleştirmede yavaş hareket etmeleri,

- Önemli sorunlara sınırlı çözüm üretebilmeleri,

- Fikirlerinin, düşünce ve çözüm önerilerinin ciddiye alınmayabilmesi,

- Uzun vadeli ve stratejik düşünme ile hareket reflekslerinin yetersiz olması,

- Başkalarından kolay etkilenebilmeleri,

- Örgütsel körlük riskini yükseltebilme potansiyeli taşımaları,

- Üst yönetime yakınlıklarının sınırlı olması ve aktif işlerde tercih edilmemeleri,

- Terfilerinin sınırlı olmasıdır.

\section{GÜMÜŞ YAKALILARIN ISTIHDAM ÖZELLIKLERi}

Bireyin kimliğinin bir parçası olarak yaptığı meslek ile varlık alanı oluşturarak kendini tanımlama ya da sosyal hayatta mesleki unvan ile konumlandırma gümüş yakalı olarak tanımlanabilecek çalışanlar için geçerli olan bir durumdur. Gümüş yakalı çalışanlar için iş süreçleri her zaman kurumsal yapının merkezinde yer almaktadır. Gümüş yakalıların samimiyet ekseninde şekillenen temel değerleri ve ortak eğilimleri ile hiyerarşik bir yapıda kimlerle nasıl ve ne düzeyde ilişki kurulabileceklerinin kesin sınırlarla bilinmesinden, bu grup çalışanlarda daha tutarlı bir istihdam şansı ortaya çıkmaktadır. Gümüş yakalıların çalıştıkları kurumla özdeşleşme, kendini çalıştı̆ı kurumla tanıtma ve hatta kurumun bir parçası olarak görme, kurumsal aidiyet gibi özellikleri çalışma ve istihdam yapılarını somut olarak desteklemektedir. Gümüş yakalılar göreceli olarak eğitim süreleri daha kısa olduğundan erken yaşta mesleki etkinliklere başlama avantajına 
sahip bulunmaktadırlar. Gümüş yakalılar çalışmaya başladıktan sonra, kendilerini geliştirmeye ihtiyaç duymaları durumunda, esnek çalışma düzeni ve nöbet sistemi ile çalışarak lisansüstü eğitimlerini de sürdürebilmektedirler.

Erken yaşta başladıkları meslek hayatlarında zamanla ortaya çıkan yeniliklere açık olma özelliği taşısalar da, söz konusu yeniliklere bağlı olarak iş anlayışları ve felsefelerinde farklılaşmayı sağlamaları kolay olmamaktadır. Nöbet sisteminde günde 12-16 saati bulan çalışma tempoları ile özel hayatları arasında denge kurma zorunlulukları kendilerini, yakın çevreleri ve ilişkilerini zorlayabilmektedir. Meslekte yıllanmış olmayı önemsiz kılan erken yaşta yaşlanma hissi, tükenmişlik, istikrarsızlık, hızlı yükselememe kaygıları ile mücadele etmek zorunda kalabilmektedirler. Alt ya da orta düzey yönetici olma yönelimleri kısıtlanabilmektedir.

\section{TARTIŞMA VE SONUÇ}

Mal ve hizmet üretim biçimlerinin her geçen gün farklılaştğı günümüz koşullarında, teknolojinin kullanımı, meslek kavramı, kurumsal hiyerarşi, çalışma biçimleri ve hatta aile yapıları köklü biçimde değişmekte ve tarihte görülmemiş biçimde kuşaklararası mesafenin açılması sürmektedir. Dönemin temel sanayisi elektronik ve bilgisayar teknolojisi olmakla birlikte, hizmet sağlama ile enformasyon üretme ve kullanma ekonomik üretimin en önemli ögeleri konumundadır (40).

Yakın dönemde yaşanan endüstriyel dönüşüme bakıldığında iş gücü performansının giderek maddiliğini yitirme eğilimine girdiği gözlemlenmekte ve günümüz toplumlarında emek, daha önce görülmemiş bir biçimde maddi olmayan emeğe doğru evrilmektedir (41). Maddi olmayan emek, entelektüel ve bilimsel-teknik bilgi temelinde, ağırıklı olarak altın yakalılarda ortaya çıkmaktadır. Bilgi çağına özgü bilginin üretilmesi, yönetilmesi, kullanılması, geliştirilmesi ve ürüne dönüştürülmesine yönelik işlemler altın yakalı çalışanlar tarafindan gerçekleştirilirken, başta sağıık hizmeti olmak üzere hizmet sektörlerinde emeğin dışsallaştrılması, insani ilişki ve sosyal iletişim gerektiren işler gümüş yakalı tanımına uygun çalışanlar tarafindan üstlenilmektedir (42).

Hizmetin dayanıksızlık özelliğine bağlı olarak hizmet sektöründe çalışanların emeği uçucu olmakta; genellikle tamamlandıkları anda tüketilmektedir. Meslek yaşamında aidiyet arayışı, iş ilişkileri bağlamında birliktelik hissi veren sosyal ağların yaygınlığı, uzun ömürlü ve bütüncül değerler arayışının işaretidir.

Sağlık hizmeti üretim sürecinde, teletıp ve yapay zekâ gibi yeni teknolojilerin entegrasyonu ve kullanımının tetiklendiği yapısal değişime rağmen, üretimin ve istihdamın belirli aşamalarında merkezden uzaklaşılması ya da iş tanımı dışına çıkılması mümkün değildir $(43,44)$. İş tanımı, rutin çalışma ve hiyerarşik bir yapıya dâhil olma durumu kesin sınırlarla belirlenmiştir. Sağlık alanında çalışanlar, nitelikleri ve çalıştikları alan itibarıyla istedikleri yerde küresel iş gücü piyasasına katılma gücüne ve serbestliğine sahip değildirler.

Çalışanların iş ortamlarının, iş ilişkilerinin ve iş yapma biçiminin değişmemesi, çalışanların sosyolojik anlamda kurumsal yapıya, mesleğe ve meslek kültürüne ait olma eğilimlerini arttırmaktadır.
Çalışanların mesleklerinin adlandırılması ve icrası yasal esaslara dayanan ortak bir mesleki kimlik göstergesi, kurumsal marka belirleyicisidir (45). Sağlık sektöründe genellikle yatay yapılanmaya izin vermeyen hiyerarşi ve ast-üst ilişkilerinin düzenlenmesi, kıyafet ve gündelik davranış kalıplarını belirleyen yazılı olan veya olmayan kurallara uyum, iş yaşamında gümüş yakalı olarak adlandırılabilecek sağlık çalışanları grubunu doğal avantajlı konuma getirmektedir (46).

Gümüş yakalı kavramı ile hemşire ve yardımcı sağlık çalışanlarına yönelik "değerli" mesajı verilmesi, hem de mesleğe yönelik özellikle "pembe yakalı" adlandırma kapsamında var olan kadın cinsiyet ayrımcılığı algısının önüne geçilmesi amaçlanmaktadır. Pembe yakalı değerlendirmesinin sağlık alanında kullanılması, sağlık hizmeti üreten meslekler için cinsiyetçi bir yaklaşım olduğu gibi profesyonel yaklaşımdan uzaklaştıran bir yaklaşım olduğu ileri sürülebilir. Tarihsel perspektifte kadınlara özgü olduğu düşünülen kariyer alanları arasında kabul edilerek "pembe yakalılar" grubuna dâhil edilen hemşirelik ve yardımcı sağlık çalışanları, mesleki ve kurumsal sadakat duygusu, uzun süreli sosyal iletişim kurma, örgüt iklimini sürdürme ve örgüt kültürünü yaşatma özellikleri ile "gümüş yakalılar" olarak anılma ile değerli kılınmayı hak etmektedir.

Hakem Değerlendirmesi: Dış bağımsız.

Bilgilendirilmiş Onam: Katılımcılardan bilgilendirilmiş onam alınmıştır.

Yazar Katkıları: Çalışma Konsepti/Tasarım- N.B.,E.Y.A.; Veri ToplamaN.B.,E.Y.A.; Veri Analizi/Yorumlama- N.B.,E.Y.A.; Yazı Taslağı- N.B.,E.Y.A.; İçeriğin Eleştirel İncelemesi- N.B.,E.Y.A.; Son Onay ve SorumlulukN.B.,E.Y.A.

Çıkar Çatışması: Yazarlar çıkar çatş̧ması beyan etmemişlerdir

Finansal Destek: Yazarlar finansal destek beyan etmemişlerdir.

Hasta Onayı: Hastanın kendisinden ve hekiminden sözlü ve yazılı izin alındı.

Peer Review: Externally peer-reviewed.

Informed Consent: Written consent was obtained from the participants

Author Contributions: Conception/Design of Study- N.B.,E.Y.A.; Data Acquisition- N.B.,E.Y.A.; Data Analysis/Interpretation- N.B.,E.Y.A.; Drafting Manuscript- N.B.,E.Y.A.; Critical Revision of ManuscriptN.B.,E.Y.A.; Final Approval and Accountability- N.B.,E.Y.A.

Conflict of Interest: Authors declared no conflict of interest.

\section{KAYNAKLAR}

1. Bozbuğa N, Güven S. Davranışların interneti. In: Bozbuğa N, Gülseçen S, editors. II. Tıpta Bilişim Kongresi, Dijital Sağlık ve Tıpta Yapay Zekâ Uygulamaları. II. Tıpta Bilişim Kongresi Özet Kitabı, 202130 Eylül - 1 Ekim; İstanbul Üniversitesi, İstanbul, Türkiye; 2021, p.9-10.

2. Bozbuğa N. Akıllı toplum, akıllı sağıık. In: Bozbuğa N, Gülseçen S, editors. II. Tıpta Bilişim Kongresi, Dijital Sağlık ve Tıpta Yapay Zekâ Uygulamaları. II. Tıpta Bilişim Kongresi Özet Kitabı, 202130 Eylül - 1 Ekim; İstanbul Üniversitesi, İstanbul, Türkiye; 2021. 
3. Marandi EH, Moghaddas EJ. Motivation factors of blue collar workers verses white collar workers in Herzberg's two factors theory. 2013:1-10. Available from: URL: https://www. pomsmeetings.org/confpapers/043/043-1565.pdf.

4. Schreurs B, Emmerik HV, Cuyper ND, Notelaers G, De Witte H. Job demands-resources and early retirement intention: Differences between blue-and white-collar workers. Economic and Industrial Democracy 2011;32(1):47-68.

5. Eriş ED, Özmen ÖNT. Bayam BY. Mavi-beyaz yaka dönemi bitti mi? İ̧ yaşamında alternatif yaka renkleri üzerine bir değerlendirme. J Yasar University 2020;15(58):259-69.

6. Najjar D, Fares P. Managerial motivational practices and motivational differences between blue- and white-collar employees: application of Maslow's theory. IJIMT 2017;8 (2):81-4.

7. Bayraktaroğlu S, Özdemir Y, Aras M, Özdemir S. Mavi yakalı çalışanlar: Neden akademik çalışmalar için cazip bir örneklem değil? İş, Güç Endüstri İlişkileri ve İnsan Kaynakları Dergisi 2015;17(3):141-57.

8. Alpaslan Danışman S. Metaphors of human resources: Collours of collars. In: Rata G, Arslan H, Runcan PL, Akdemir A, editors. Interdisciplinary Perspectives on Social Sciences. Newcastle; Cambridge Scholars Publishing; 2014.p.3-10.

9. Yılmaz Şener M. Can women have gold collars? In: Work life for educated women in Turkey. International Conference on Knowledge and Politics in Gender and Women's Studies. Middle East Technical University, Ankara, Türkiye; 2015.p.689-98.

10. Holland PJ, Hecker R, Steen J. Human resource strategies and organisational structures for managing gold-collar workers. J Eur Industrial Trainig 2002;6(2-3-4):72-80.

11. Roongrerngsuke $S$, Liefooghe A. Attracting goldcollar workers: comparing organizational attractiveness and work-related values across generations in China, India and Thailand. Asia Pacific Business Review 2013;19(3):337-55.

12. Yılmaz Şener M. Kadınlar altın yaka takabilir mi? Türkiye'de eğitimli kadınlar için iş hayatı. Sosyoloji Dergisi 2016;36:13-40.

13. Christiana MBV. Strategic Stress Management of Gold Collars. Dwarka, New Delhi; Educreation Publishing, 2017.

14. McLaughlin DB. Electronics and the future of work: The impact on pink and white collar workers. The Annals of the American Academy of Political and Social Science 1983;470:152-62.

15. Hunt G. Sex differences in a pink-collar occupation. Relations Industrielles / Industrial Relations 1993;48(3):441-60.

16. Rung MC. Paternalism and pink collars: Gender and federal employee relations, 1941-50. The Business History Review 1997;71(3):381-416.

17. Öğüt A. Türkiye'de kadın girişimciliğin ve yöneticiliğin önündeki güçlükler: Cam tavan sendromu. Girişimcilik ve Kalkınma Dergisi 2006;1:56-78.

18. Kahraman AB, Tunçdemir NO, Özcan A. Toplumsal cinsiyet bağlamında hemşirelik bölümünde öğrenim gören erkek öğrencilerin mesleğe yönelik algıları. Sosyoloji Araştırmaları Dergisi 2015;18(2):108-44.

19. Özel Bilim I, Bülez A. Cam tavandan yansımalar. İnsan ve Toplum Bilimleri Araştırmaları Dergisi 2018;7(1):48-58.

20. Koldemir B, Yapıcı M. A study on role of green port implementation and "greencollar" workers in port facilities. The Second Global Conference on Innovation in Marine Technology and the Future of Maritime Transportation, Muğla, Türkiye; 2016, p.413-8.
21. Harvey DM, Bosco SM, Emanuele G. The impact of "greencollar workers" on organizations. Management Research Review 2010;33(5):499-511.

22. Pinderhughes R. Green collar jobs: Work force opportunities in the growing green economy. Race, Poverty \& the Environment 2006;62-3.

23. Ehmcke W, Philipson G, Kold-Christensen C. Who are the green collar workers? A definition and taxonomy. Australia; Connection Research and DECC NSW, 2009.

24. McClure LA, LeBlanc WG, Fernandez CA, Fleming LE, Lee DJ, Moore KJ, Caban-Martinez AJ. Green collar workers: An emerging workforce in the environmental sector. Journal of Occupational and Environmental Medicine 2017;59(5):440-5.

25. Chen CJ, Moore KJ, Fernandez CA, Arheart KL, LeBlanc WG, Cifuentes M, McClure LA, Christ SL, Fleming LE, Lee DJ, CabanMartinez AJ. Chemical and physical exposures in the emerging US green collar workforce. J Occupational Environmental Medicine 201759(5):e91-e96.

26. Hutchings K, Zhu KC, Cooper BK, Zhang Y, Shao S. Perceptions of the effectiveness of training and development of "grey-collar" workers in the People's Republic of China. Human Resource Development International 2009;12(3):279-96.

27. Chellappa LR, Balasubramaniam A, Indiran MA, Rathinavelu PK. A qualitative study on attitude towards smoking, quitting and tobacco control policies among current smokers of different socioeconomic status. J of Family Med Primary Care 2021;10(3):1282-7.

28. Baliç B, Gemlik N, Arslanoğlu A. (). Dijital yakalı sağlık çalışanlarının iş yaşamından beklentileri üzerine nitel bir araştırma. Sağlık Akademisyenleri Dergisi 2020;7(3):209-16.

29. Indrianil B. Emerges of no collar work force and challenges from HR respectives. indiansjournal.com 2018;9(1):54-7. DOI:10.5958/2231-069X.2018.00008.2

30. Alvi S, Mclntyre D. The open-collar worker, Canadian Business Review (CAB) 1993;20(1):21-4.

31. Kırpık G. COVID-19 pandemisinin insan kaynakları üzerindeki etkisinin akademi, medya ve iş dünyası perspektifinden incelenmesi. Manas Sosyal Araştırmalar Dergisi 2020;9(4):2393406.

32. Reid AS. Financial crime in the Twenty-First Century: The rise of the virtual collar criminal. In: Ryder N, editor. White Collar Crime and Risk. Palgrave Studies in Risk, Crime and Society. London; Palgrave Macmillan; 2018. https://doi.org/10.1057/978-1-137-47384-4_9

33. Bozbuğa N. Olağanüstü durumlarda sağlık sektöründeki kadın çalışan için yeni istihdam alanları: Proaktif ve inovatif yaklaşımlar. In: Uslu YD, Ayanoğlu F, editors. Ulusal Sağlık Sektöründe Kadın İstıhdamı Çalıştayı (Pandemi Özel). İstanbul; İstanbul Medipol Üniversitesi Yayınları; 2021. p.23-31.

34. Solomon WSD, Bahadory M, Jeyarajasingam AV, Rutkowsky SA, Boritz C. Synthesis and study of silver nanoparticles. J Chem Edu 2007;84(2):322-5.

35. Fidan E. Tarih öncesi dönemlerde Anadolu'da kullanılmış olan maden yatakları. Ore deposits of Anatolia used in Prehistorical Times. Yer Altı Kaynakları Dergisi (Journal of Underground Resources) 2016;9:49-59.

36. Yavuz G, Türetken I. Nanoteknolojik dezenfektanların heterotrofik biyofilmler üzerine etkisi. Türk Hijyen ve Deneysel Biyoloji Dergisi 2018;75(4):323-32. 
37. Bozbuğa, N. Sağlıkta risk ve risk süreç yönetimi. In: Bozbuğa N, Yakıncı C, editors. Hasta Güvenliği ve Risk Yönetimi. Malatya; İnönü Üniversitesi Yayınları; 2020.p.1-9.ISBN 978-605-7853-50-9.

38. İşsever H. Sağlık çalışan güvenliği ve risk yönetimi. In: Bozbuğa N, Yakıncı C, editors. Hasta Güvenliği ve Risk Yönetimi. Malatya; İnönü Üniversitesi Yayınları; 2020.p.45-52.ISBN978-605-7853-50-9.

39. Bozbuğa N, Kutbay E. Yaygın e-öğrenme tabanlı sağlık eğitimi: Oyunlaştırma ve sağlık okuryazarlığı. In: Bozbuğa N, Gülseçen S, editors. Tıp Bilişimi. İstanbul; İstanbul Üniversitesi Yayınevi; 2021.p.569-96. E-ISBN 978-605-07-0773-1

40. Schwerdt G, Ichino A, Ruf O, Winter-Ebmer R, Zweimüller J. Does the color of the collar matter? Employment and earnings after plant closure. Economics Letters 2010;108(2):137-40. DOI:101016/j.econlet.2010.04.014

41. Hoplamazian GJ, Knobloch-Westerwick S. The color of their collar: Effects of social status portrayal in advertising on selfesteem. Howard J Communications 2014;25(4):378-98, DOI: 10.1080/10646175.2014.955930
42. Bozbuğa, N. Sağlıkta inovasyon risk yönetimi. In: Bozbuğa N, Yakıncı C, editors. Hasta Güvenliği ve Risk Yönetimi. Malatya; İnönü Üniversitesi Yayınları; 2020. p.437-42. ISBN 978-605-7853-50-9

43. Bozbuğa N. Tıbbi cihaz ve malzemelere genel bakış. In: Bozbuğa N, Yakıncı C, editors. Tıbbi Cihaz ve Malzemeler. Malatya: İnönü Üniversitesi Yayınları; 2019.p.3-10. ISBN 978-605-7853-30-1

44. Bozbuğa N. Kalp ve damar cerrahisinde kullanılan tıbbi cihaz ve malzemeler. In: Bozbuğa N, Yakıncı C, editors. Tıbbi Cihaz ve Malzemeler. Malatya: İnönü Üniversitesi Yayınları;2019. p.137-42. ISBN 978-605-7853-30-1

45. Alarçin EY. Sağlık hizmetlerinde marka risk yönetimi. In: Bozbuğa N, Yakıncı C, editors. Hasta Güvenliği ve Risk Yönetimi. Malatya; İnönü Üniversitesi Yayınları;2020.p.511-6.ISBN978-605-7853-50-9

46. Alarçin $E Y$, Sözen $A B$, Bozbuğa $N$, İşsever H. Hekim kıyafetlerine ilişkin hasta tercihleri eğilimi. Sağık Bilimlerinde İleri Araştırmalar Dergisi 2021;4(2):7-20. 